\title{
Mice Lacking Metabotropic Glutamate Receptor 5 Show Impaired Learning and Reduced CA1 Long-Term Potentiation (LTP) But Normal CA3 LTP
}

\author{
You-Ming Lu, ${ }^{1}$ Zhengping Jia, ${ }^{1}$ Christopher Janus, ${ }^{1}$ Jeffrey T. Henderson, ${ }^{1}$ Robert Gerlai, ${ }^{1}$ \\ J. Martin Wojtowicz, ${ }^{2}$ and John C. Roder ${ }^{1}$ \\ ${ }^{1}$ Samuel Lunenfeld Research Institute, Mount Sinai Hospital, Toronto, Ontario M5G 1X5, Canada, and 2Department of \\ Physiology, University of Toronto, Toronto, Ontario M5S 1A8, Canada
}

\begin{abstract}
Class I metabotropic glutamate receptors (mGluRs) have been postulated to play a role in synaptic plasticity. To test the involvement of one member of this class, we have recently generated mutant mice that express no mGluR5 but normal levels of other glutamate receptors. The CNS revealed normal development of gross anatomical features. To examine synaptic functions we measured evoked field EPSPs in the hippocampal slice. Measures of presynaptic function, such as paired pulse facilitation in mutant CA1 neurons, were normal. The response of mutant CA1 neurons to low concentrations of $(1 S, 3 R)-1$-amino-cyclopentane-1,3dicarboxylic acid (ACPD) was missing, which suggests that mGluR5 may be the primary high affinity ACPD receptor in these neurons. Long-term potentiation (LTP) in mGluR5 mutants was significantly reduced in the NMDA receptor (NMDAR)-dependent pathways such as the CA1 region and dentate gyrus of the
\end{abstract}

hippocampus, whereas LTP remained intact in the mossy fiber synapses on the CA3 region, an NMDAR-independent pathway. Some of the difference in CA1 LTP could lie at the level of expression, because the reduction of LTP in the mutants was no longer observed 20 min after tetanus in the presence of 2-amino5-phosphonopentanoate. We propose that mGluR5 plays a key regulatory role in NMDAR-dependent LTP. These mutant mice were also impaired in the acquisition and use of spatial information in both the Morris water maze and contextual information in the fear-conditioning test. This is consistent with the hypothesis that LTP in the CA1 region may underlie spatial learning and memory.

Key words: hippocampus; gene targeting; long-term potentiation; metabotropic glutamate receptor 5; spatial learning; snyaptic function
Recent experiments raise the possibility that G-proteincoupled metabotropic glutamate receptors (mGluRs) may be involved in long-term potentiation (LTP) (Bashir et al., 1993), a potential cellular mechanism for learning and memory (Bliss and Collingridge, 1993). Of the eight mGluRs that have been molecularly characterized (Nakanishi, 1994), those linked to phosphatidylinositol turnover (Abe et al., 1992) have been implicated most strongly in LTP (Pin and Duvoisin, 1995). For example, the application of the mGluR agonist $(1 S, 3 R)-1$ amino-cyclopentane-1,3-dicarboxylic acid (ACPD) was reported to potentiate NMDA- and AMPA-mediated currents directly, and its application during tetanus enhanced LTP (O'Connor et al., 1995). When ACPD was combined with subthreshold tetanic stimulation, or when NMDA and ACPD were co-applied, LTP was induced in the hippocampus (Zheng and Gallagher, 1992). Conversely the mGluR, antagonist $(R, S)$ - $\alpha$-methyl-4-carboxylphenylglycine (MCPG) inhibited tetanus-induced LTP in both the CA1 region and at the perforant pathway in the dentate gyrus (Bashir et al., 1993; Riedel and Reymann, 1993; Richter-Levin et al., 1994). MCPG only

Received Nov. 11, 1996; revised April 8, 1997; accepted April 11, 1997.

This work was supported by grants to J.R. from the Medical Research Council, Ontario Mental Health Foundation, and Networks of Centers of Excellence in Neuroscience. J.M.W. was supported by the Medical Research Council. We thank Oral Okem for behavioral observations.

Z.J. made an equal contribution.

Correspondence should be addressed to John C. Roder, Samuel Lunenfeld Research Institute, Mount Sinai Hospital, 600 University Avenue, Room 854, Toronto, Ontario M5G 1X5, Canada.

Copyright (C) 1997 Society for Neuroscience $\quad 0270-6474 / 97 / 175196-10 \$ 05.00 / 0$ blocked the initial LTP but not LTP arising from subsequent stimulations (Bortolotto et al., 1994). This gave rise to the molecular switch model in which both NMDA receptors (NMDARs) and mGluRs must be co-activated to induce LTP. This is controversial, because other studies showed a lack of effects of MCPG on LTP (Chinestra et al., 1993; Manzoni et al., 1994). The subtype of mGluR involved remains unknown, because these agonists and antagonists are not subtype-specific. Expression studies revealed that the distribution patterns of the group I receptors, mGluR1 and 5, are nearly complementary. For example, in the CA1 area of the hippocampus, mGluR5 is the predominant receptor, whereas mGluR1a is absent (Baude et al., 1993; Shigemoto et al., 1993). mGluR5 is found predominantly in the postsynaptic dendrites and spines of CA1 cells on EM analysis (Romano et al., 1995). One study using gene-targeting techniques has demonstrated that mGluR1 is not required for NMDAR-dependent LTP in CA1 (Conquet et al., 1994), although it modulates mossy fiber and cerebellar LTD (Aiba et al., 1994). To address the involvement of mGluR5, the other group I receptor, we generated mutant mice lacking mGluR5 and report here that NMDARdependent LTP is partially impaired in two separate pathways, and this correlates with selective impairments in spatial learning and memory in different tasks. Mossy fiber LTP in CA3, in contrast, is presynaptic and does not rely on postsynaptic NMDARs (Nicoll and Malenka, 1995). This form of LTP was also compared in our mGluR5-deficient mice and was found to be normal. Our study implicates a role for mGluR5 in the regulation of postsynaptic NMDAR-dependent pathways and 
supports the idea that CA1 LTP is necessary for spatial learning and memory.

\section{MATERIALS AND METHODS}

Mutant mice. A null mutation in the mGluR5 gene was created by gene targeting (Z. Jia and J. C. Roder, unpublished observations) in our 129 strain of R1 embryonic stem (ES) cells (Nagy et al., 1993). Targeted ES clones were aggregated with CD1 morulae, and chimeric males were mated with CD1 females. All mice were derived from F2 litters of crosses between heterozygotes. The LTP phenotype in mGluR5 mutants could not be accounted for by differential inheritance of background genes because: (1) the 129 and CD1 parental lines had equal LTP levels $($ mean \pm SEM) at $63 \pm 6 \%$ above baseline $(n=22)$ and $64 \pm 5 \%(n=$ 36), respectively (Jia et al., 1996); (2) an F2 population from a wild-type $129 \times \mathrm{CD} 1$ cross produced mice with LTP at $69 \pm 4 \%$ above baseline $(n=36)$, which is outside the distribution of $\mathrm{mGluR} 5^{-1-}$ mice at $50 \pm$ $5 \%$ above baseline $(n=19)$; and (3) a backcross of the mGluR5 mutant 129 chimera to the 129 strain also showed diminished LTP in CA1 (data not shown). Therefore, the loss of mGluR5 shows a similar phenotype in these different mouse strains.

Neuroanatomy. Mice were deeply anesthetized with sodium pentobarbitol (Somnitol, $80 \mathrm{mg} / \mathrm{kg}$, i.p.) and perfused transcardially with $20 \mathrm{ml}$ of PBS, followed immediately by $40 \mathrm{ml}$ of $4 \%$ paraformaldehyde in $0.1 \mathrm{M}$ PBS (pH 7.4). Whole brains were then removed and post-fixed in $4 \%$ paraformaldehyde at $4^{\circ} \mathrm{C}$ for an additional $48 \mathrm{hr}$. Samples were then placed in a solution of $30 \%$ sucrose for $24-36 \mathrm{hr}$ at $4^{\circ} \mathrm{C}$. After embedding, $30 \mu \mathrm{m}$ serial cryostat sections were obtained at intervals of $150 \mu \mathrm{m}$ for mGluR5 $^{+/-}$and mGluR5 $^{-1-}$ as well as wild-type (mGluR5 ${ }^{+/+}$) littermates of similar genetic background and age (45-60 d postnatally). Sections were taken through the entire brain in both the horizontal and sagittal planes ( $n=3$ animals per genotype) at $-20^{\circ}$ through the desired region using a Reichert-Jung 2800 Frigocut E cryostat.

Electrophysiology. Hippocampal slices $(400 \mu \mathrm{m})$ were cut from 3- to 7-week-old mice and were placed in a holding chamber for at least $1 \mathrm{hr}$. A single slice was then transferred to the recording chamber and submerged and superfused with artificial CSF (ACSF, $2 \mathrm{ml} / \mathrm{min}$ ) that had been saturated with $95 \% \mathrm{O}_{2}-5 \% \mathrm{CO}_{2}$ (Gerlai et al., 1995). The composition of the ACSF was (in mM): $124 \mathrm{NaCl}, 3 \mathrm{KCl}, 1.25 \mathrm{NaH}_{2} \mathrm{PO}_{4}, 2$ $\mathrm{MgCl}_{2}, 2 \mathrm{CaCl}_{2}, 26 \mathrm{NaHCO}_{3}, 10$ dextrose. Field potential recordings were performed with micropipettes at $30 \pm 2^{\circ}$ filled with ACSF. Synaptic field responses were measured by taking either the slope of the rising phase between 5 and $95 \%$ or between 5 and $60 \%$ of the peak response. The 5-95\% field EPSP (fEPSP) measurement contains both NMDARand AMPA receptor (AMPAR)-mediated components (15 and 85\% respectively), whereas the $10-60 \%$ fEPSP measurements contain solely the AMPAR-mediated component. Whole-cell recordings were obtained using the "blind method" and were performed in current-clamp or voltage-clamp mode. The internal pipette solution for voltage clamp contained (in mM) 132.5 cesium gluconate, $17.5 \mathrm{CsCl}, 0.05$ EGTA, 10 HEPES, 2 Mg-ATP, 0.2 GTP, and 5 QX-314, pH 7.4, (292 mOsm); for current clamp it contained (in $\mathrm{mM}) 132.5$ potassium gluconate (7.5 $\mathrm{K}^{+}-\mathrm{MeSO}_{4}, 10$ HEPES, 0.2 EDTA, $0.2 \mathrm{NaCl}, 2 \mathrm{Mg}$-ATP, and $0.2 \mathrm{CTP}$, pH 7.4, $290 \mathrm{mOsm})$.

Synaptic currents and field potentials were evoked by bipolar tungsten electrodes and recorded with an Axopatch-1D patch clamp amplifier and monitored by computer. Responses were evoked at a frequency of $0.1 \mathrm{~Hz}$ in CA1 and dentate gyrus and $1 \mathrm{~Hz}$ in the mossy fiber pathway. Tetani to evoke LTP in CA1 consisted of four trains of $100 \mathrm{~Hz}$ stimulation lasting $500 \mathrm{msec}$, at an intertrain interval of $10 \mathrm{sec}$. LTP in the dentate gyrus was measured in the presence of $100 \mu \mathrm{M}$ picrotoxin. LTP in mossy fiber CA3 was evoked by one train of $100 \mathrm{~Hz}$ stimulation for $500 \mathrm{msec}$ Tetanus was delivered in the presence of $50 \mu \mathrm{M} \mathrm{D}-(-)$-2-amino-5phosphonopentanoic acid (APV) to prevent contamination with the NMDA-dependent pathway converging on CA3 neurons. In whole-cell voltage clamps the AMPA-mediated component was taken as the difference between EPSCs recorded in the presence and absence of CNQX 5 msec after the stimulus. The NMDA component was measured in the presence of CNQX $50 \mathrm{msec}$ after the stimulus in medium containing 1.3 $\mathrm{mM} \mathrm{Mg}^{2+}$ and $100 \mu \mathrm{M}$ picrotoxin.

Subjects. For behavioral studies all mice were bred in our animal colony and were housed in groups of four or five animals in cages $(33 \times 15 \times 12$ $\mathrm{cm})$ in a room with an ambient temperature of $20 \pm 1^{\circ} \mathrm{C}$ and $12: 12 \mathrm{hr}$ light/dark cycle with lights on at 7 A.M. Animals were tested at the age of $3 \pm 0.5$ months between 10 A.M. and 4 P.M. The control animals were always littermates of mutants, and both control and mutant groups were sex-balanced.

The open field test. The circular apparatus (for details of design, see Janus et al., 1995) was placed $30 \mathrm{~cm}$ above the floor in the center of a $3.05 \times 3.05 \mathrm{~m}$ room. The illumination in the room was provided by centrally placed in-ceiling fluorescent lights. A mirror $(80 \times 60 \mathrm{~cm})$ placed at an angle on the wall enabled unobtrusive observation of the behavior of the mice. The observer was present in the room, recording subjects' behavior on a computer.

All subjects were individually tested in one 5 min session. Each subject was introduced to the apparatus in the same place of the arena near the wall. The following behaviors were recorded: (1) locomotor behavior, measured both as the time (seconds) a subject moved at least half the distance of its body length and the number of fields crossed (the hind legs of the subject crossing a line as the criterion); (2) pause, including brief immobility periods; (3) rearing, a subject body is raised supported only by hind legs and a tail; (4) wall leaning, like rearing, but front legs were touching the wall of the apparatus; and (5) grooming, which included fur cleaning and/or combing and face washing. Locomotor behavior, pause, and rearing were recorded separately for the central and peripheral fields of the arena. Also, a latency of central field exploration (seconds) was recorded.

Water maze. Mice were tested in the hidden and visible platform versions of the test, as described previously (Gerlai et al., 1995). The pool was at least $40 \mathrm{~cm}$ from the nearest extramaze cue. The pretraining session began with a subject placed on the platform for $15-20 \mathrm{sec}$. The animal was then placed in the water and allowed to swim for $15-20 \mathrm{sec}$, after which it was returned to the platform for another $15 \mathrm{sec}$. Finally, the mouse was given three trials of climbing the platform. In each of these trials, the experimenter pulled the mouse gently at the base of its tail from the platform into water and allowed it to climb the platform again. After the pretraining session commenced, the subject was returned into a holding cage for $30 \mathrm{sec}$ before the first training trial began.

Each subject was given six training trials per day. Each trial began by placing the mouse in the water, near and facing the wall of the pool. The starting points for each subject were chosen randomly from any of the three quadrants other than the one with the platform. Each subject was allowed $60 \mathrm{sec}$ to find the platform. If it failed to reach the platform within that time, it was guided by the experimenter to the platform. Subjects were always allowed a $10 \mathrm{sec}$ rest on the platform. For each subject, the latency to reach the platform was recorded. The subjects that did not reach the platform during a trial were assigned a latency of $60 \mathrm{sec}$. In the visible platform version of the water maze, the submerged platform was indicated with a black flag $(5 \times 3 \mathrm{~cm})$, and its location was varied randomly between four possible quadrants of the pool for each subject and trial of a session. In the hidden platform test, the platform location was always in the same position (southeast quadrant).

Contextual fear conditioning. The conditioning chamber consisted of one closed side $(21 \times 20 \times 19 \mathrm{~cm})$ of a shuttle box (Shuttle-Scan SC II, Omnitech Electronics, Inc.) with a speaker and a light in the lid. The floor consisted of stainless steel bars that were connected to a computer, which controlled the duration of a test session, timing, and intensity and duration of shock or sound. Background noise was $52 \mathrm{~dB}$. Single subjects were allowed to explore the chamber for $120 \mathrm{sec}$ before the onset of a discrete conditioned stimulus (CS), which consisted of continuous sound $(3600 \mathrm{~Hz}, 95 \mathrm{~dB})$ lasting $30 \mathrm{sec}$. During the last $2 \mathrm{sec}$ of this CS period a subject was exposed to an unconditioned stimulus (US), a continuous foot shock $(0.75 \mathrm{~mA})$. Approximately $24 \mathrm{hr}$ later, subjects were given a $5 \mathrm{~min}$ contextual conditioning test in the same chamber in which they were trained. The CS test $(6 \mathrm{~min})$ was performed $2 \mathrm{hr}$ later. During this test the chamber was altered by covering the floor and walls with gray plastic, adding an additional source of light and changing its olfactory characteristics. During the first $3 \mathrm{~min}$ of the test the CS was not presented (pre-CS stage), after which subjects were exposed to $3 \mathrm{~min}$ of the tone. Fear response was assessed by recording the subjects' freezing response. Freezing was defined as absence of any locomotor activity, except for respiratory movements, sometimes slight head movements, and occasional tail rattling. The animals were usually in a crouching position. In addition to freezing, the subjects' locomotion, pause, wall leaning, rearing and grooming were recorded. The chamber was cleaned with $70 \%$ alcohol after each subject was tested.

Statistical analysis. Data from males and females and from heterozygous and wild-type mice were pooled together, respectively, because no significant differences were found between these groups on any obtained measure. The behavioral data were analyzed using ANOVA 
with repeated measures for the time factor. In cases of departure from sphericity, in repeated measures of ANOVA, degrees of freedom were reduced by the Greenhouse-Geisser correlation (Stevens, 1992). Whenever multiple, interrelated behavioral measures were analyzed, a multivariate ANOVA (MANOVA) was used (Stevens, 1992). Planned comparisons between control and mutant mice were carried out using $t$ tests. Only significant results are reported in Results. Electrophysiological experiments (group comparisons in LTP) were performed on 5 min blocks of data within the last $30 \mathrm{~min}$ of LTP recording using repeated measures ANOVA. All variance values in the text and figure legends represent SEM.

\section{RESULTS \\ CNS development is normal}

In a previous study we showed that the mGluR5 null allele was inherited in a mendelian fashion, and mGluR $5^{-1-}$ mice showed undetectable levels of mGluR5 protein but normal levels of other glutamate receptors (Z. Jia and J. C. Roder, unpublished observations). Immunocytochemistry using antibodies specific for both mGluR5 isoforms (Minikami et al., 1993) showed no mGluR5 in the hippocampus but normal mGluR1 $\alpha$ expression.

To examine mGluR5 mutant mice for potential developmental abnormalities, several sets of serial sections were obtained from mGluR5 $5^{-/-}$and mGluR5 ${ }^{+/-}$control littermates. Thioninstained $10 \mu \mathrm{m}$ serial paraffin sections were taken through the entire extent of the cranium at $300 \mu \mathrm{m}$ intervals, in both the sagittal and coronal planes $(n=3)$, for both $\mathrm{mGluR} 5^{-/-}$and mGluR5 ${ }^{+/-}$littermates (45-60 d postnatally). Thirty micrometer serial cryostat sections were also obtained at intervals of $150 \mu \mathrm{m}$ for mGluR5 ${ }^{+/+}$and mGluR5 ${ }^{-/-}$mice through the entire horizontal and sagittal planes $(n=3$ for each plane). As shown for regions known to express mGluR5 (hippocampus, cortex, striatum, and olfactory bulb), mutant mice revealed no significant neurodevelopmental abnormalities for these, or other, structures within the CNS (Fig. 1). In addition, $30 \mu \mathrm{m}$ serial cryostat sections (coronal plane) of mGluR5 $5^{-/-}$and $\mathrm{mGluR} 5^{+/+}$mice $(300 \mu \mathrm{m}$ intervals) were stained for cytochrome $c$ oxidase activity, a gross indicator of the level of presynaptic input. These also showed no significant differences between the two groups $(n=2$ animals per group) (data not shown). Thus, mGluR5 $5^{-/-}$mice were found to be without major neuroanatomical abnormalities, possessing all major neuroanatomical loci and fiber pathways in normal proportions.

\section{mGluR5 is the main high-affinity ACPD receptor in CA1}

The mGluR agonist ACPD has been shown to produce several effects, including a reversible depression of synaptic transmission in the hippocampus (Pin and Duvoisin, 1995). In the CA1 area, multiple subtypes of mGluRs have been implicated in the depression in fEPSP, namely groups I and III (Gereau and Conn, 1995). Because ACPD is not active at group III mGluRs, its depressant effects are likely caused by group I (mGluR1/5). This depression was not altered in the mGluR1 mutant mice (Aiba et al., 1994). To examine whether ACPD-induced depression is mediated through mGluR5, the fEPSP in the CA1 region of the hippocampus was compared, between the mGluR5 mutants and wild-type controls, in the presence of various concentrations of ACPD (Fig. 2A). In wild-type slices, 10, 25, 50, or $100 \mu \mathrm{M}$ ACPD, 10 min after agonist application, decreased fEPSP by $14.3 \pm 1.21,28.8 \pm 2.6,55.5 \pm$ 4.6, and $98.1 \pm 9.2 \%$, respectively. However, the effects of ACPD on fEPSP were very much attenuated in the mutant slices. For example, $25 \mu \mathrm{M}$ ACPD did not decrease fEPSP at all in mGluR5 mutants, and $50 \mu \mathrm{M}$ ACPD produced only a $12 \pm 1.0 \%$ depression in fEPSP. However, application of $300 \mu \mathrm{M}$ ACPD decreased
fEPSP by $64.4 \pm 5.4 \%$, even in the mutant slices. Such an apparent shift in the sensitivity to ACPD indicates that the effects of ACPD on fEPSP, at low concentrations $(<50 \mu \mathrm{M})$, may be exclusively mediated by the activation of mGluR5. Other mGluRs, such as mGluR1, may be activated at higher ACPD concentrations.

The lack of effect of low concentrations of ACPD (25 or 50 $\mu \mathrm{M})$ on CA1 fEPSP in the mGluR5 mutant mice was also supported by our whole-cell recordings from individual neurons, in which the application of $50 \mu \mathrm{M}$ ACPD had no effect on EPSP in the mutants, whereas the same concentration of ACPD produced $64.2 \pm 5.1 \%(n=4)$ depression of EPSP in the wild-type controls $(n=4)$ (Fig. $2 B$ ). Neuronal depolarization in response to ACPD in wild-type controls was $8.3 \pm 0.76$ $\mathrm{mV}(n=4)$, compared with no changes in mutants. In the dentate gyrus, in contrast to the CA1 region, the response to ACPD $(25$ or $50 \mu \mathrm{M})$ application in slices was indistinguishable between mGluR5 mutant mice and wild-type controls (Fig. $2 C)$. In addition, all depression was completely blocked by the addition of $1 \mathrm{~mm} \mathrm{MCPG}$ in the dentate region.

To examine whether the lack of actions of ACPD on fEPSP in the CA1 region of mGluR5 mutant mice was selective, the effects of both L-AP4, a selective agonist for group III mGluRs, and carbachol, an agonist for the muscarinic acetylcholine receptor, were compared between mutants and wild-type controls. The depression in fEPSP after application of various concentrations of L-2-amino-4-phosphonobutyric acid (AP4), or carbachol, was the same in these two groups, suggesting that functional effects mediated by group III mGluRs and muscarinic acetylcholine receptors was not altered in the mutant mice (Fig. 2D,E).

\section{Altered synaptic responses in mGluR5 mutants}

The efficacy of excitatory synaptic transmission in the Schaffer collateral-commissural pathway in the CA1 region of the hippocampus in the mGluR5 mutant and control mice was examined. The amplitude, time course, and current-voltage relations of the AMPA component (CNQX-sensitive) of synaptic currents, obtained with whole-cell recordings, revealed normal responses in the mutant mice (Fig. 3A,B). However, the NMDA receptor channel current, expressed as the ratio to the non-NMDA component, was significantly $(p<0.01)$ reduced in the mutant slices at the holding potentials between -20 and $+60 \mathrm{mV}$ (Fig. $3 C$ ), although the NMDA receptors retained their usual voltage dependence (Fig. 3B). The extent of paired pulse facilitation, a measure of presynaptic function, showed no significant difference over an interpulse interval range of 20-500 msec (Fig. 3D). Finally, the input-output curves, constructed by plotting the slope of fEPSP versus presynaptic fiber-volley amplitude, were identical (data not shown).

\section{Decrease in hippocampal LTP in mGluR5 mutants}

To examine the possible consequences of the reduced NMDA currents, we examined the ability of three hippocampal pathways to undergo LTP in mice lacking mGluR5 (Fig. 4). In this series of experiments fEPSPs were measured at 5-95\% of the peak, and LTP was induced by four trains of tetani. In the CA1 region, the magnitude of LTP was significantly reduced (by 35\%) in the mutant slices compared with the wild-type controls. Averaged LTP in the last $30 \mathrm{~min}$ after tetanus was $50.2 \pm 5.7 \%$ above the $(100 \%)$ baseline from 19 mutant slices (19 animals) and $77.6 \pm$ $10.2 \%$ above the baseline from 19 wild-type slices (19 animals) $\left[F_{(1,32)}=6.45 ; p=0.016\right]$ (Fig. $4 A$ ). When we measured fEPSP in 
A
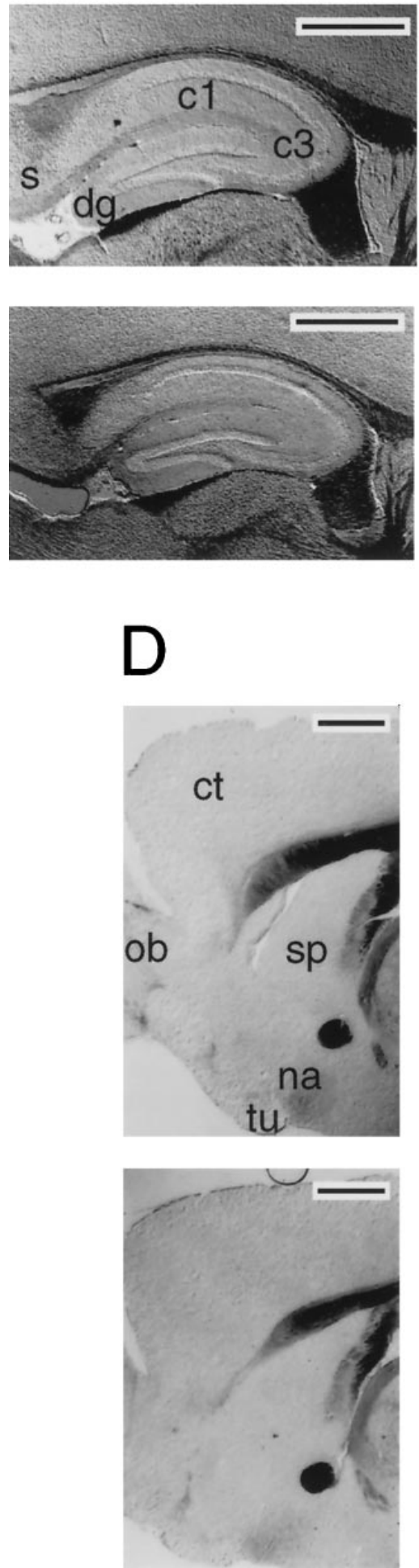

B
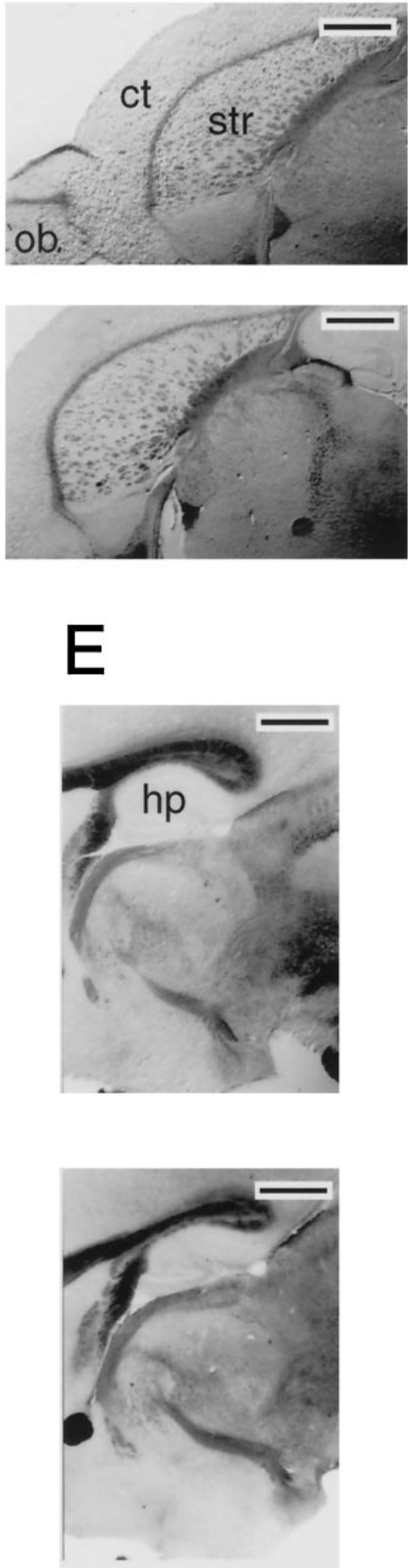

C
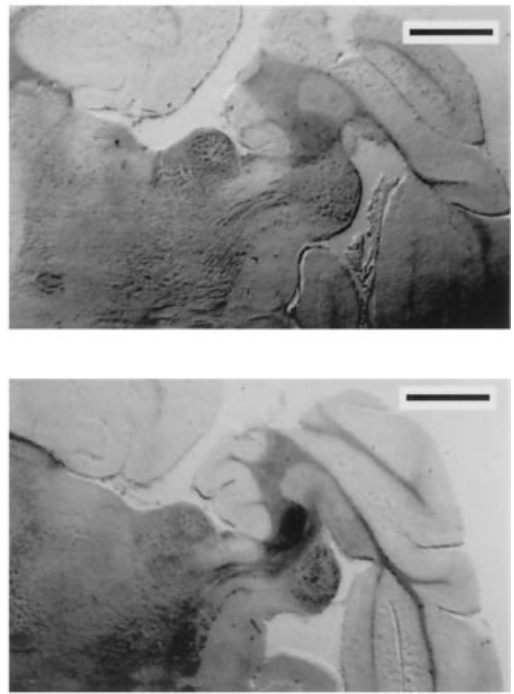

F
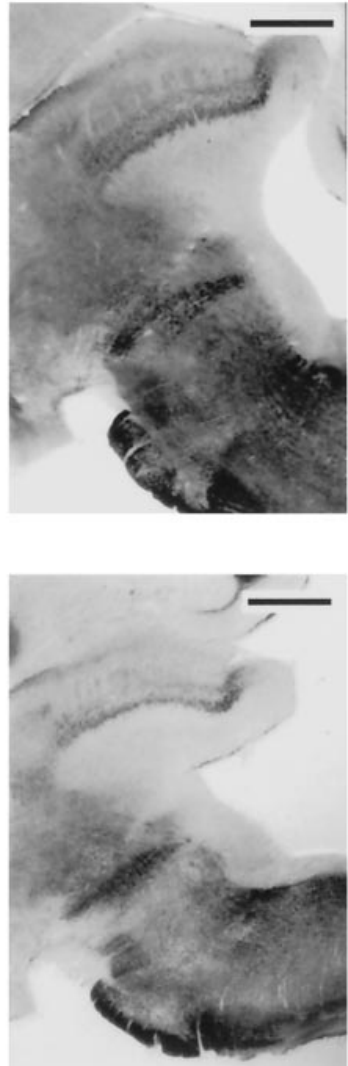

Figure 1. Neuroanatomy in mGluR5 mice: pairwise comparisons of adult mGluR5 $5^{+/-}$(top panels) and mGluR5 ${ }^{-/-}$(bottom panels) littermates. Thirty micrometer cryostat sections at comparable levels are shown. $A$, Parasagittal sections showing the hippocampal formation (right, rostral; left, caudal). $B$, Horizontal sections through the forebrain and thalamus $(2.8 \mathrm{~mm}$ ventral to the dorsal aspect of brain). $C$, Horizontal sections through the hindbrain (4.5 $\mathrm{mm}$ ventral to the dorsal aspect of brain). $D$, Parasagittal sections of the forebrain (300 $\mu \mathrm{m}$ from midline). E, Parasagittal sections showing structures of the diencephalon, hippocampus, and splenium of the corpus callosum (300 $\mu \mathrm{m}$ from midline). $F$, Parasagittal sections of the caudal aspect of the brain, showing regions of the superior and inferior colliculus and brainstem ( $450 \mu \mathrm{m}$ from the midline). Scale bars, $A, 500 \mu \mathrm{m} ; B-F, 1000 \mu \mathrm{m}$. Labeled structures represent regions previously shown to express high levels of mGluR5. $c 1$, Hippocampal subfield CA1; $c 3$, hippocampal subfield CA3; $c t$, neocortex; $d g$, dentate gyrus; $h p$, hippocampus; $n a$, nucleus accumbens; $o b$, olfactory bulb; $s$, subiculum; $s p$, medial septal region (low in mGluR5 expression); str, striatum; $t u$, olfactory tubercle. 

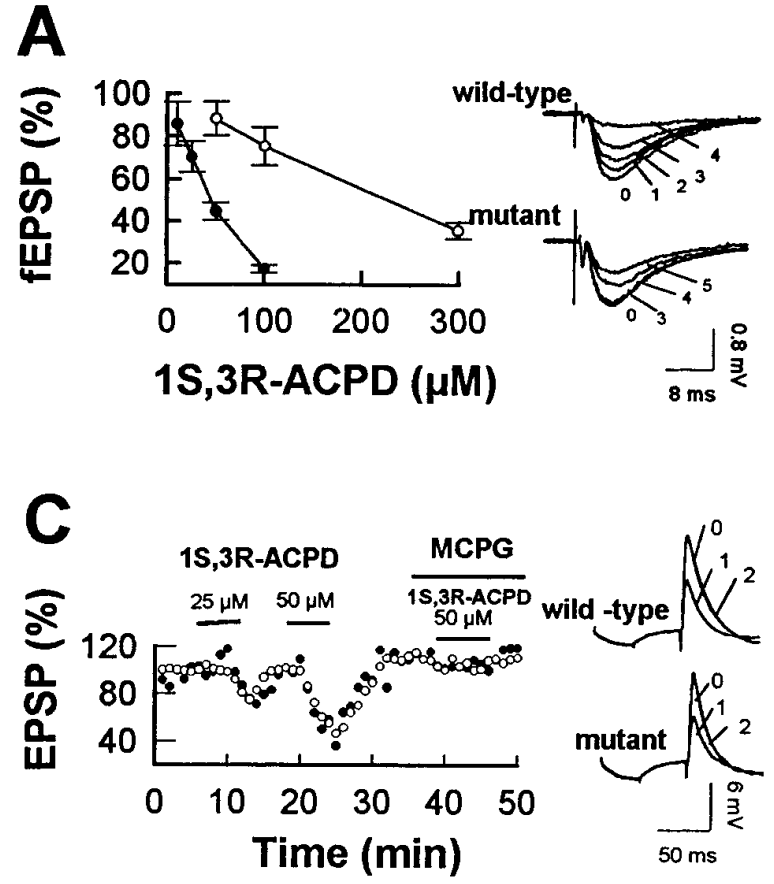

B
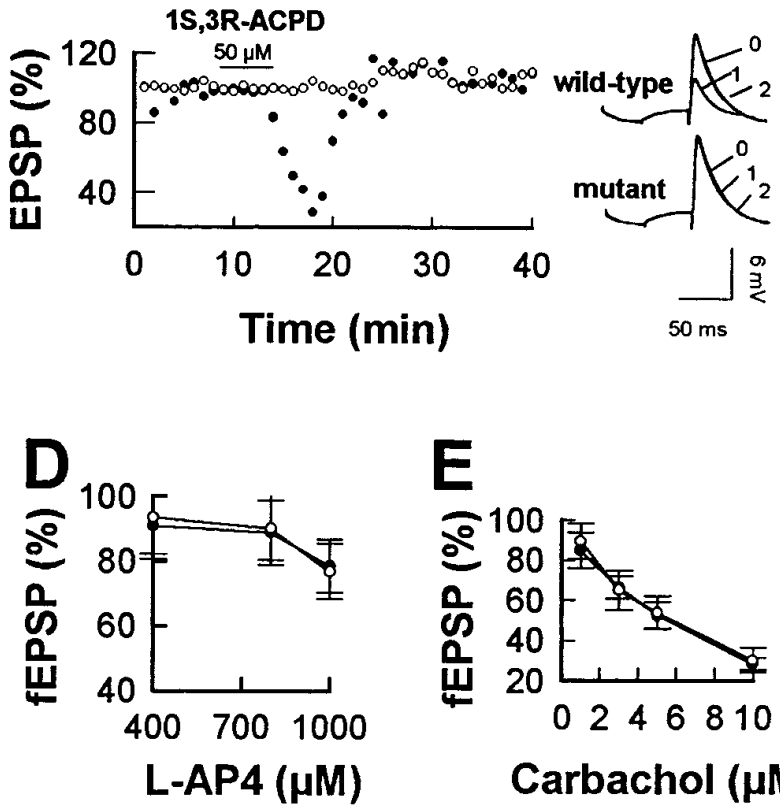

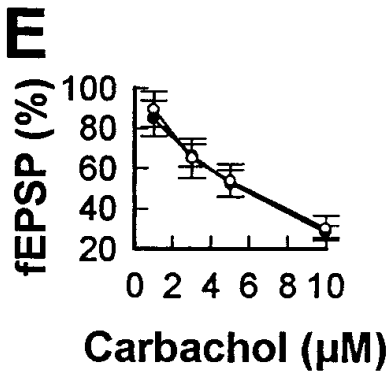

Figure 2. Decreased response to ACPD in mGluR5 mutants. $A$, Mean \pm SEM depression of fEPSP slope induced by ACPD. Data are expressed as mean percentages of the control values in mutant mice $(\bigcirc$, six slices, six animals $)$ and wild-type mice $(\boldsymbol{\bullet}$, six slices, six animals). Traces taken from representative experiments show the effects of ACPD on evoked fEPSP. Each trace is an average of six sweeps recorded immediately before drug application $(0)$ or after $10 \mathrm{~min}$ in the agonist at concentrations of 10 (1), 25 (2), 50 (3), $100(4)$, and 300 (5) $\mu \mathrm{M}$. B, Whole-cell current-clamp recording showing the time course of EPSP depression by bath application of ACPD in a single wild-type $(\bullet)$ or mutant $(\bigcirc)$ CA1 cell, representative of four cells. The constant current $(20$ pA) hyperpolarizing pulse preceding the EPSP did not give any evidence of the input resistance changes during ACPD applications. $C$, Representative time courses of EPSP depression in whole-cell current-clamp recordings in the medial perforant pathway of the dentate granule neurons in the presence or absence of ACPD and $1 \mathrm{mM} \mathrm{MCPG}$ in wild-type $(\bullet)$ and mutant $(O)$ mice. Insets in $B, C$, Representative EPSP before $(0)$, during $(1)$, and after $(2)$ ACPD application. $D$, Mean \pm SEM percent fEPSP after L-AP4 application to CA1 from control $(\bullet)$ and mutant $(O)$ mice $(n=4)$. E, Mean fEPSP after carbachol addition to control $(\bullet)$ and mutant $(\bigcirc)$ mice (six slices, three animals).

CA1 at $10-60 \%$ of the peak, LTP in wild-type mice was $168 \pm$ $14 \%$ (19 slices from 19 animals) (Table 1), which was not significantly different $(p=0.28)$ than LTP in mutants, $148 \pm 11 \%(19$ slices from 19 animals). The slope measurement at 5-95\% of the peak, in Figure 4, included both AMPA receptor- and NMDA receptor-mediated components, because addition of 2-amino-5phosphonopentanoate (AP5) removed $\sim 15 \%$ of the potential, whereas CNQX removed $85 \%$ of the potential. Therefore, about half of the missing LTP in CA1 may be accounted for at the level of induction. The other missing portion may lie at the level of

Table 1. Analysis of LTP in CA1 in control and mGluR5 mutant mice using differential slope parameters

\begin{tabular}{llll} 
& \multicolumn{3}{l}{ Slope measurement } \\
\cline { 2 - 4 } mGluR5 genotype & $\begin{array}{l}5-95 \% \text { of } \\
\text { slope }^{a}\end{array}$ & $\begin{array}{l}5-95 \% \text { of } \\
\text { slope in } \\
\text { AP5 }^{a}\end{array}$ & $\begin{array}{l}10-60 \% \text { of } \\
\text { slope }\end{array}$ \\
\hline +/+ Genotype & $177.6 \pm 10.2 ;$ & $164.8 \pm 16 ;$ & $168 \pm 14 ;$ \\
& $n=19$ & $n=8 ;$ & $n=19 ;$ \\
-/- Genotype & $150.5 \pm 5.7 ;$ & $149.9 \pm 12 ;$ & $148 \pm 11 ;$ \\
& $n=19$ & $n=8$ & $n=19$ \\
+/+ vs -/- & $p=0.016$ & $p=0.431$ & $p=0.244$
\end{tabular}

${ }^{a}$ AP5 $(50 \mu \mathrm{M})$ was added $20 \mathrm{~min}$ after tetanic stimulation.

${ }^{b} p$ values for a comparison with the first column,,$++ 5-95 \%$ slope, four-train tetanic stimulation. $n$ represents the number of slices. Each mouse yielded one or two slices. expression, because subsequent experiments in $50 \mu \mathrm{M}$ AP5 $20 \mathrm{~min}$ after LTP induction removed some of the difference between wild-type and mGluR5 mutant mice (Table 1). These data indicate that the NMDA receptor-mediated component contributed significantly to the field EPSP, and the reduced LTP recorded with fEPSP in mGluR5 mutants was likely attributable to elimination of this component.

A significant reduction in the degree of LTP was also seen in the medial perforant pathway of the dentate gyrus, where the averaged LTP from nine slices (five animals for each genotype) was $40.4 \pm 5.7 \%$ above baseline for the mutants, compared with $66.9 \pm 9.2 \%$ for the wild-type controls $\left[F_{(1,12)}=6.2 ; p=0.028\right]$ when fEPSP was measured at $5-95 \%$ of the peak (Fig. $4 B$ ). However, when the mossy fiber LTP in the CA3 region was compared between the mutants and the wild-type controls, we could not detect any significant difference in either magnitude or time course (Fig. 4C). The averaged mossy fiber LTP from nine slices (five animals for both groups) was $60.3 \pm 14.7 \%$ for mutants and $50.6 \pm 5.8 \%$ for wild-type controls $\left[F_{(1,12)}=0.31\right.$, NS]. Therefore, LTP was produced in all three pathways of the hippocampus but was selectively attenuated in CA1 and the dentate gyrus.

\section{Descriptive behavioral observations}

The mGluR5 mutants were indistinguishable in their weight and morphology. No changes in locomotor and other behaviors were apparent in home cages. When moved to new cages, mGluR5 mutants were soon engaged in normal exploratory behavior, saw- 

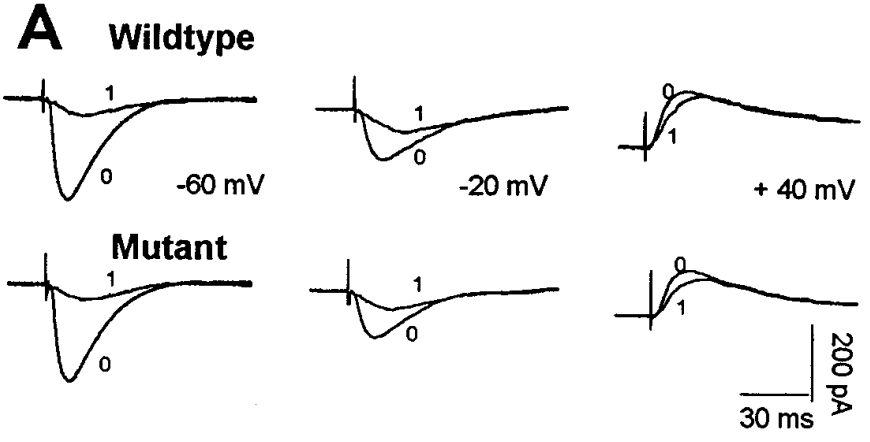
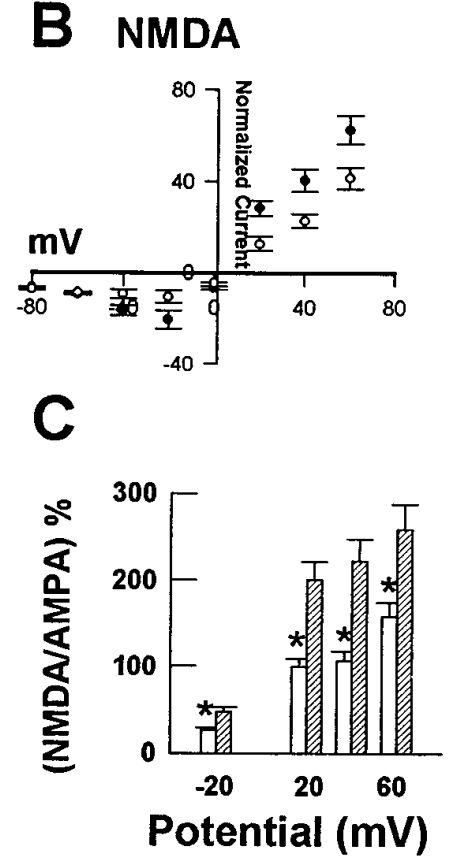

Figure 3. Reduced NMDA component of synaptic transmission in hippocampal slices from mGluR5 mutant mice. $A$, The EPSC traces were recorded from CA1 neurons in whole-cell voltage-clamp mode and were averages of six successive sweeps before $(0)$ and $20 \mathrm{~min}$ after (1) the addition of $10 \mu \mathrm{M} C N Q X$. The holding membrane potentials are indicated between the traces. $B$, Averaged amplitudes of AMPA- and NMDAmediated responses in mGluR5 $5^{+/+}(\mathbf{O})$ and $\mathrm{mGluR} 5^{-/-}(\bigcirc)$ mice, normalized to the $5 \mathrm{msec}$ peak of AMPA EPSC at $-80 \mathrm{mV}$, which was $342.6 \pm 38 \mathrm{pA}(n=10)$ in control and $318.8 \pm 34 \mathrm{pA}(n=11)$ in mutant mice. The AMPA component at $-80 \mathrm{mV}$ was taken as $100 \%$, and all other current amplitudes were scaled and expressed as a percentage of the AMPA current. $C$, Data in $B$ shown as the NMDA component of EPSCs that differed between wild-type (hatched bars) and mutants (open bars). *Significant difference $(p<0.01, t$ test). $D$, Magnitude of the paired pulse facilitation of fEPSPs in the CA1 area of the two groups (six slices from three animals for each genotype). $P 1$, First response; $P 2$, second response applied at the indicated intervals on the $x$-axis.

dust, digging, rearing, and cage top climbing. Mutant males were also engaged in occasional bursts of fighting, at the same rate as males in control groups. However, mGluR5 mutants were unusually reactive to handling. They were difficult to catch in their home cage and often jumped off the experimenter's hand or off the cage. This reactivity to handling showed slow habituation. To ensure a blind experiment all cages were coded, and handling and behavior recording were carried out by different experimenters.

\section{Behavior in the open-field test}

To examine motility and response to a novel environment, control and mutant mice were observed in an open-field test. Because no
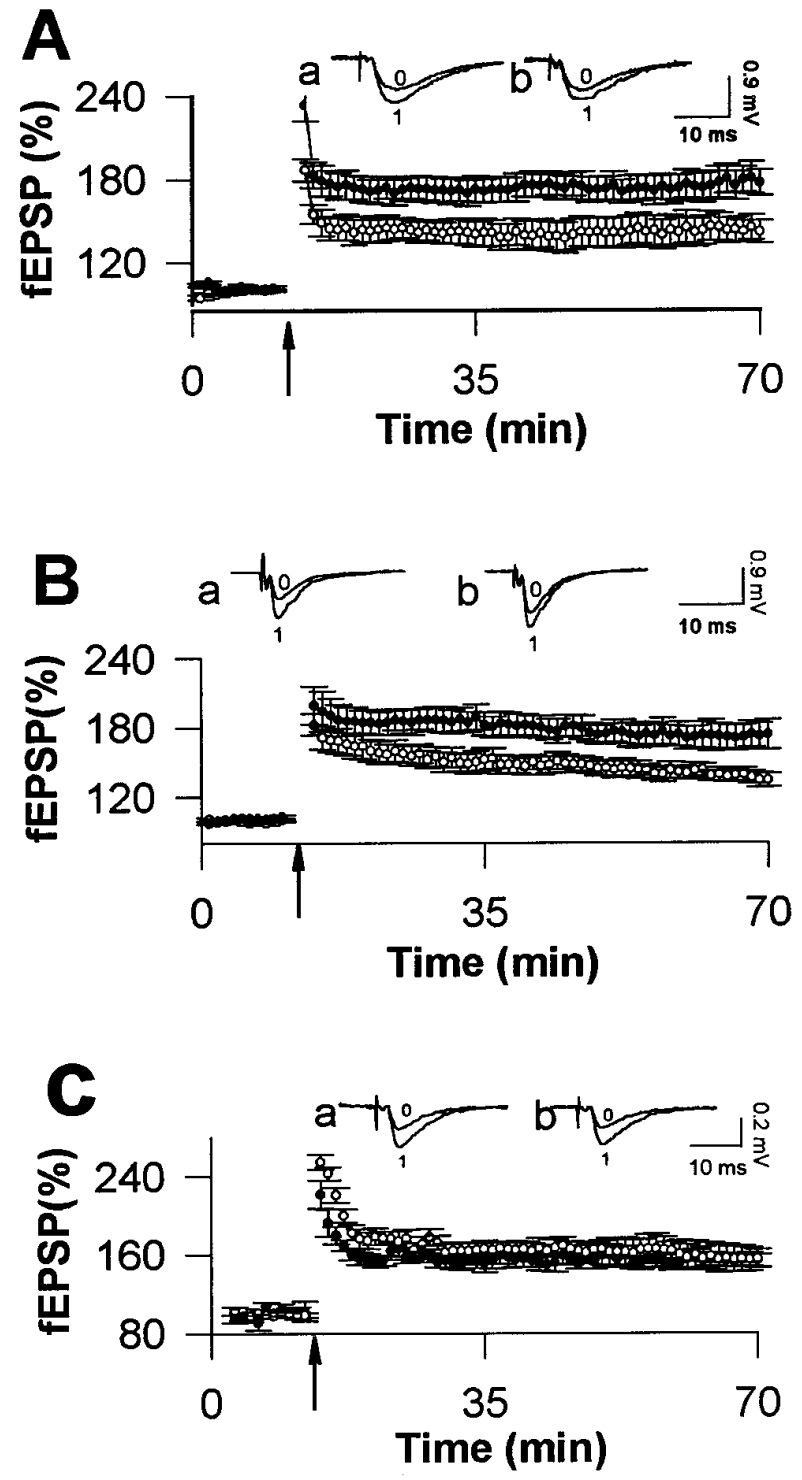

Figure 4. Reduced LTP in NMDA-dependent pathways in mGluR5 mutant mice. The mean \pm SEM of the $5-95 \%$ slope of the fEPSP, normalized with respect to 10 min immediately preceding the tetanus $(\uparrow)$ for hippocampal slices obtained from control $(\bullet)$ or mutant $(\bigcirc)$ mice in area CA1 $(A)$, the dentate gyrus medial perforant pathway $(B)$, and the CA3 mossy fiber pathway $(C)$. LTP in CA1 was induced by four trains of $100 \mathrm{~Hz}$ tetanic stimulation. LTP in the dentate gyrus was induced by four trains of tetanus in the presence of $100 \mu \mathrm{M}$ picrotoxin. LTP in CA3 was induced by one tetanic train in the presence of $50 \mu \mathrm{M}$ AP5. Representative traces (average of six sweeps) of fEPSP obtained immediately before $(0)$ and $60 \mathrm{~min}$ after (1) the tetanus are shown for a control mouse $(a)$ and mutant mouse $(b)$, respectively.

differences were found between fields crossed and time of walking or between behaviors in the periphery and center of the arena, we removed field crossing from the analysis and pooled peripheral and central field data together. The analysis of behaviors (walking, pausing, wall leaning, rearing, and grooming) performed by mice did not reveal any significant differences between groups [MANOVA, $F_{(5,16)}=0.25 ; p=0.93$ ] (Table 2). In addition, the mGluR5 mutants did not differ from controls in their latency of central field exploration $\left[t_{(9)}=0.33 ; p>0.05\right]$. The results indicated that mGluR5 mutant mice did not differ from control 
A
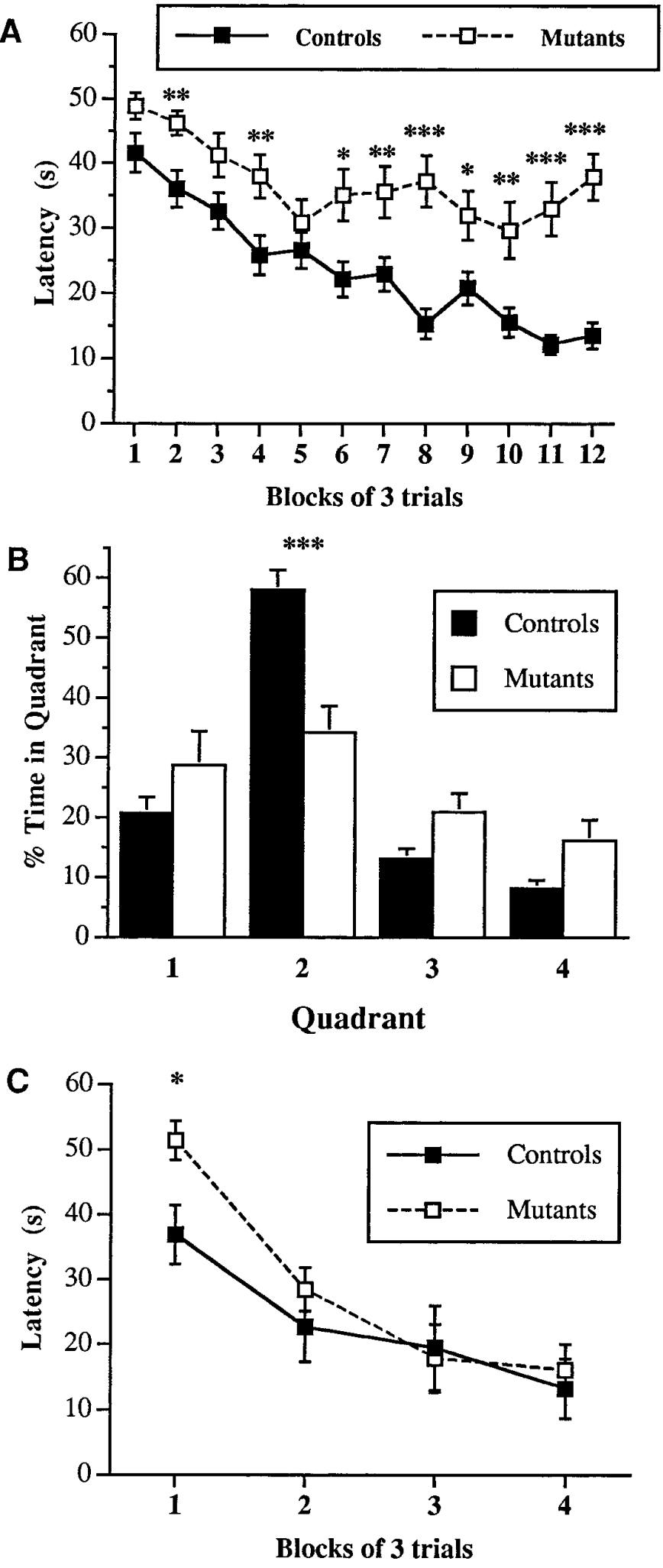

Figure 5. Performance of mGluR5 mutants was impaired in the water maze. $A$, mGluR5 mutants and control mice were trained with two blocks of three trials per day (for $6 \mathrm{~d}$ ) in the water maze. The average time to reach the hidden platform in the pool was plotted against three-trial blocks. A significant difference was found between groups. $B$, Percentage of time spent searching in each quadrant of the pool during the probe trail given $1 \mathrm{~d}$ after the last training trial. Quadrants: 2, target quadrant (southeast); 1 , adjacent to the right (northeast); 3 , adjacent to the left animals in their locomotor and exploratory behavior in the new environment.

\section{Decreased learning acquisition in mGluR5 mutants in the water maze}

Control $(n=27)$ and mGluR5 mutant $(n=22)$ mice were trained for 6 days in the hidden platform version of the water maze with six trials per day. Analysis of three-trial blocks revealed a significant difference in learning between control and mutant mice $\left[F_{(1,47)}=20.45 ; p<0.001\right]$ and between days $\left[F_{(3,235)}=28.43 ; p<\right.$ $0.001]$. Also, group by day and group by block interactions were significant $\left[F_{(3,235)}=3.88 ; p<0.01 ;\right.$ and $F_{(1,47)}=12.79 ; p<$ 0.001 , respectively]. Both interactions indicated a significant difference in learning acquisition between groups. Throughout the experiment mutant mice always had longer latencies in finding the platform, but beyond the third day of training their latencies leveled at 35-40 sec, whereas the control mice showed a steady decrease, reaching an average of $10-15 \mathrm{sec}$ by the end of training (Fig. 5A). Planned comparisons revealed that the most significant differences between groups occurred after the third day of training (sixth three-trial block; Fig. $5 A$ ). To elucidate further the nature of the above interactions, an analysis of simple effects with trend analysis and an effect size (Stevens, 1992) was performed for each group. For the control group we found a significant decrease in latencies over time $\left[F_{(5,286)}=17.94 ; p<0.001\right]$, with $92 \%$ of the variance $(\eta 2=0.916)$ accounted for by the change in learning. Two trends were found significant, linear and quadratic $\left[F_{(1,26)}=\right.$ 74.8; $p<0.001$; and $F_{(1,26)}=5.2 ; p<0.05$, respectively]. The linear trend accounted for $74 \%$ and the quadratic accounted for $17 \%$ of the variance in learning acquisition. Accordingly, there was a significant change in learning in the mutant group $\left[\left(F_{(5,231)}\right.\right.$ $=5.63 ; p<0.001]$, with $69 \%(\eta 2=0.688)$ of the variance explained by the change in learning. Again, only linear and quadratic trends were found to be significant $\left[F_{(1,21)}=9.5 ; p<0.01\right.$; and $F_{(1,21)}=15.9 ; p<0.001$, respectively], accounting for $31 \%$ and $43 \%$ of the variance. In conclusion, although both groups learned to find the hidden platform, the character of learning change was different in controls (mostly linear) and mutants (mostly quadratic). At the end of the training period, all animals were given one probe trial, in which the platform was removed and the mice were allowed to search the pool for $60 \mathrm{sec}$. The

Table 2. Normal locomotor behaviors performed by mGluR5 mutant mice in 5 min open-field test

\begin{tabular}{lcc} 
Behavior & $\begin{array}{c}\text { Controls } \\
(n=12)\end{array}$ & $\begin{array}{c}\text { mGluR5 mutants } \\
(n=10)\end{array}$ \\
\hline Walking & $202.2 \pm 12.5$ & $186.2 \pm 12.8$ \\
Pause & $59.4 \pm 14.6$ & $74.3 \pm 16.0$ \\
Wall leaning & $24.7 \pm 3.8$ & $25.9 \pm 5.9$ \\
Rearing & $3.8 \pm 2.5$ & $4.4 \pm 1.9$ \\
Grooming & $6.2 \pm 1.0$ & $5.9 \pm 1.3$
\end{tabular}

Data represent the average total time $(\mathrm{sec}) \pm$ SEM. See text for detailed descriptions of observed behaviors.

(southwest); 4, opposite (northwest). Control animals searched selectively, and significantly longer, for the platform in the training quadrant (2) than mutants. $C$, The average time to reach the visible platform in each three-trial block ( $2 \mathrm{~d}$ of testing) is presented. ANOVA with repeated measures did not reveal any significant differences between mutants and controls. * $p<0.05 ;{ }^{* *} p<0.01 ;{ }^{* * *} p<0.001$. 
A
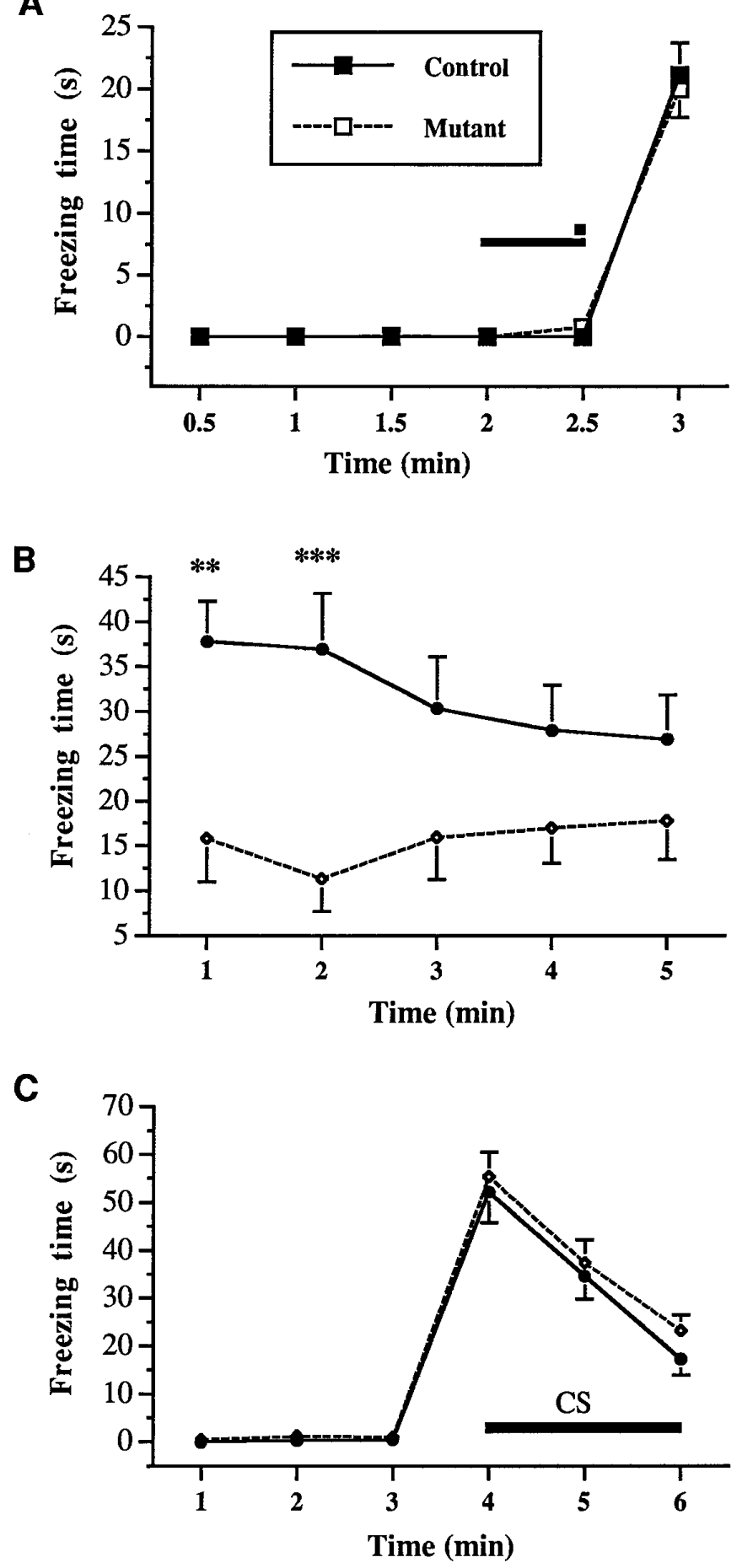

Figure 6. Contextual fear conditioning is impaired in mGluR5 mutants. $A$, Duration of freezing during the training phase of fear conditioning. Mutant mGluR5 and control mice showed a comparable amount of freezing immediately after the foot shock. The solid line indicates the duration of the tone (CS); squares indicate the $2 \mathrm{sec}$ footshock (US). $B$, The mice were tested for contextual conditioning $24 \mathrm{hr}$ after training. Mutant mice showed significantly less freezing than controls when returned to the training chamber. $C$, A control tone $(C S)$ conditioning test was carried out in a new context $2 \mathrm{hr}$ after the context test. Both mutants and controls showed no freezing in a new context and comparable amounts of freezing when a tone $(C S)$ was presented in a new context. $* * p<0.01, * * * p<0.001$. control mice spent more time in the target quadrant than in the other three quadrants $\left[F_{(2,78)}=59.21 ; p<0.001\right]$, whereas mutant mice did not (Fig. $5 B$ ). The search time in the target quadrant by the mutant mice was significantly shorter than by controls $(p<$ 0.001 ), and the mutant mice crossed the platform site less frequently than the controls $[1.05 \pm 0.26$ and $2.74 \pm 0.38 \%$ for mutants and controls, respectively; $\left.t_{(47)}=3.52 ; p<0.001\right]$.

In the visible platform version of the water maze test, control $(n=10)$ and mutant $(n=10)$ mice were tested for $2 \mathrm{~d}$, because their learning rate in this test progressed rapidly. The analysis performed on three-trial blocks showed no apparent differences between mutant and control mice in the latency to reach the platform. The significant results of day $(p<0.001)$, block $(p<$ $0.001)$, and day by block interaction $(p<0.001)$ confirmed rapid learning across training blocks in both groups. A significant group by day interaction $(p<0.05)$ was caused by longer latencies of mutant mice $(p<0.05)$ during the first day of training (Fig. 5C).

\section{Decreased contextual fear conditioning in mGluR5 mutants}

This paradigm (Philips and LeDoux, 1992) allowed us to test: (1) the subjects' unconditioned response to shock (US), (2) their ability to associate simple pairing between a shock and a discrete stimulus-like tone (CS), and (3) the context in which they received the shock. Because the changes in duration and frequency of freezing were similar, we present only the total time of freezing responses for control mice $(n=15)$ and mGluR5 mutant mice $(n=15)$ (Fig. 6). The control and mutant subjects showed a similar freezing response to shock during training, which suggests similar perception and response to aversive foot shock. The two groups were also not different in exploratory behaviors during the training session. In the context test performed $24 \mathrm{hr}$ after training, the mutant mice showed a significant reduction in the freezing time, especially at the beginning of the test (Fig. $6 B$ ) [MANOVA, $\left.F_{(1.28)}=8.7 ; p<0.01\right]$. Both control and mutant mice showed similar freezing to tone in the CS test carried out $2 \mathrm{hr}$ after the context test (Fig. 6C). The groups also did not differ in other exploratory behaviors during each phase (first 3 min with no CS and second 3 min with CS) of the CS test.

\section{DISCUSSION}

Our data show that mGluR5-deficient mice develop normally at a gross neuroanatomical level but exhibit changes in the synaptic responses of hippocampal neurons, which may be associated with deficits in spatial learning and memory.

The responses of hippocampal neurons to class III agonists (L-AP4) or carbachol, which activate muscarinic acetylcholine receptors, were normal. However, the responses to ACPD in CA1 were dramatically reduced in mGluR5 mutants. In contrast, the ACPD effects were not altered in mGluR1-deficient mice (Aiba et al., 1994). Therefore, mGluR5 is perhaps the best candidate to fulfill the role of the ACPD receptor, because it is localized both presynaptically and postsynaptically at CA1 synapses (Romano et al., 1995). In contrast to the CA1 area, the response to ACPD at various concentrations in the perforant pathway of the dentate gyrus was indistinguishable between the wild-type and mGluR5 mutant mice. Because the depression effect of ACPD was completely blocked by addition of MCPG in both groups, it is reasonable to speculate that such an effect is mediated by mGluR1, mGluR2, or additional unknown members of group I mGluRs. Analysis of mGluR1- and mGluR1/5-double-deficient mice will be valuable in distinguishing these possibilities. The inhibitory ACPD 
action on mGluR5 may not be relevant to LTP, because LTP was decreased in the dentate gyrus, where mGluR5 did not seem to respond to ACPD.

The results also suggest that the mGluR5 receptor plays an important regulatory role in LTP in NMDA-dependent pathways in the hippocampus. Although it is generally agreed that the induction of LTP in both the CA1 region and dentate gyrus is dependent on activation of NMDA receptors, whether mGluRs are also required in this process has been controversial (Bliss and Collingridge, 1993; Nakanishi, 1994). The pharmacological profile of the effects of various agonists and antagonists of mGluRs suggests that group I mGluRs (mGluR1 and mGluR5) are potential candidates for LTP modulation. Given the fact that mGluR $1 \alpha$ is mainly expressed in the interneurons in the CA1 region of the hippocampus, but not in pyramidal neurons (Baude et al., 1993), its role as a postsynaptic modulator of CA1 LTP is not likely. Indeed, when the mGluR1 gene was mutated, LTP could still be elicited with full strength in NMDA-dependent pathways of the hippocampus but was impaired in NMDA-independent LTP in the mossy fiber synapses on CA3 (Conquet et al., 1994; see Aiba et al., 1994). Although these studies indicate that mGluR1 does not need to be co-activated to induce or modulate LTP in either the CA1 area or dentate gyrus, it does not rule out the involvement of other members of the group I family. The only other known member of group I mGluRs, mGluR5, fits the pharmacological profile and is richly expressed in pyramidal neurons in the CA1 area. It is therefore the best candidate molecule to serve as a modulator in the induction of LTP in CA1, and, indeed, our data show partially reduced LTP in the absence of mGluR5. Similar results were obtained at the perforant pathway in the dentate gyrus. The fact that the mossy fiber LTP was normal in the mGluR5 mutants but severely diminished in the mGluR1 mutants suggests that mGluR5 is important in specifically modulating NMDA receptor-dependent LTP, whereas mGluR1 specifically modulates NMDA receptor-independent LTP. The mechanism by which mGluR5 modulates LTP could involve its regulation of NMDAR function at the induction and/or expression level of LTP. Hence in mGluR5 mutant mice we saw a reduction in NMDA receptor-mediated current in the CA1 area of the hippocampus. fEPSPs measured at $5-95 \%$ of the slope contained an NMDAR-mediated component $(15 \%)$, which was removed in AP5. Therefore, about half of the missing LTP in CA1 could lie at the level of LTP induction. The remainder could lie at the level of LTP expression, because addition of AP5 after tetanus reduced LTP and removed part of the difference in LTP between wildtype and mGluR5 mutants. In intracellular studies presented elsewhere we show that the NMDA component of LTP, after tetanus, is missing in mGluR5 mutants, whereas the AMPA component is normal (Z. Jia, Y. M. Lu, and J. C. Roder, unpublished observations).

If LTP is involved in learning and memory, then the mGluR5 mutants should show some impairment in learning and memory tasks, because hippocampal NMDAR-dependent LTP was significantly reduced in the mGluR5 mutant mice. Our results show that indeed mGluR5 mutant mice were significantly impaired in two different spatial learning tasks, which are known to depend on an intact hippocampus (Morris, 1990; Philips and LeDoux, 1992). In the water maze (Morris, 1990), subjects must actively escape from an aversive situation, whereas in contextual fear conditioning the subjects show passive fear response (freezing) in the context in which they previously experienced shock (Philips and LeDoux, 1992). Each of the above paradigms include nonspatial control tests in which nonspatial learning was evaluated. The performance of mGluR5 mutants in all nonspatial control tests was comparable to that of control animals. Because we did not find any changes in motor and exploratory activities of mGluR5, the impairment in their spatial learning seems to be selective. The learning acquisition impairment in the water maze was confirmed in the probe trial. Although controls persistently searched for the platform, spent significantly longer time in the target quadrant, and more often crossed the platform side, the mutants did not stay significantly longer in the target quadrant and never persistently searched the area of the platform site. The longer latencies of mutants were not caused by their floating in water, inactivity near the wall, or thigmotaxic swimming along the wall. Also, their motivation, visual acuity, swimming abilities, and learning of the association between a single cue and the platform position were the same as in control animals when the platform was marked by a flag. Mutants also showed impairment in the fear-conditioning test, which requires the association of background contextual information with the US, but showed normal learning of association between a tone (CS) and a shock (US). Animals from both groups explored a shock chamber during training at the similar rate and responded identically to US. Our results are compatible with the injection of the class I mGluR5 antagonist MCPG into rats, which reduced spatial learning, whereas a class I agonist applied after learning facilitated memory recall (Riedel, 1996).

A variety of other studies have tried to test correlations between LTP and learning and memory (Martinez and Derrick, 1996). Pharmacological, physiological, and surgical perturbations have been performed, but the results are inconclusive. However, all genetic disruptions (nine of nine) that impaired spatial learning and memory also impaired LTP in the Schaeffer collateral pathway to CA1. This includes the genes for fyn (Grant et al., 1992), $\alpha-\mathrm{Ca}^{2+}$-calmodulin kinase II (CaMKII) (Silva et al., 1992), cAMP response element binding protein- $\alpha \delta$ (Bourtchuladze et al., 1994), PKC- $\gamma$ (Abeliovitch et al., 1993), NMDAR2A (Sakimura et al., 1995), CaMKII-D286 (Bach et al., 1995; Mayford et al., 1996), calbindin D-28 (Molinari et al., 1996), and NMDAR1 (Tsien et al., 1996). Gene deletion systems that excised the NMDAR1 gene only in the CA1 region several weeks after birth also yielded mice that showed impaired LTP and spatial learning and memory (Tsien et al., 1996). Conversely, gene disruptions that did not impair spatial learning and memory did not alter the Schaeffer collateral pathway in the spatial LTP on CA1 cells (Huang et al., 1995; Nosten-Bertrand et al., 1996). This emphasizes the importance of the Schaeffer collateral pathway in learning and memory. Two studies tended to dissociate LTP and learning and memory in the perforant path and mossy fiber pathways of the hippocampus. The disruption of the thy- 1 gene disrupted granule cell LTP in the perforant pathway of the hippocampus (Nosten-Bertrand et al., 1996), whereas learning and memory were normal. Disruption of PKA selectively decreased CA3 LTP in the mossy fiber pathway, but learning and memory were also normal (Huang et al., 1995). The above evidence and our own data here, in which mGluR5 mutants showed normal mossy fiber LTP but decreased spatial learning, provide a double dissociation between them. Therefore, the best remaining correlation between LTP and learning and memory resides in the CA1 region. In the absence of perforant paths, or mossy fiber LTP in the system, information relevant to spatial learning could reach CA1 directly from the entrohinal cortex (Huang et al., 1995).

These genetic correlations between LTP and some forms of learning and memory are also supported by a locally applied NMDAR 
antagonist (APV), which blocked induction of LTP in the hippocampus and seemed to block "spatial" learning but not a simple visual association task (Morris, 1990; Davis, 1992). However, more recent studies show that APV only impairs spatial learning in task-naive animals, whereas subjects pretrained in a spatial task resist this inhibition (Bannerman et al., 1995). Because both NMDA antagonists APV and $(2 R, 4 R, \quad 5 S)$-2-amino-4,5(1,2-cyclohexyl)-7phosphonoheptano acid blocked LTP but failed to block spatial learning in pretrained rats (Saucier and Cain, 1995), the relationship between LTP and spatial learning is not direct. Whether NMDAR is necessary for learning spatial strategies or simply refining motor skills rather than spatial maps requires more work.

\section{REFERENCES}

Abe T, Sugihara H, Nawa H, Shigemoto R, Mizumo W, Nahanishi S (1992) Molecular characterization of a novel metabotropic glutamate receptor, mGluR5, coupled to inositol phosphate $/ \mathrm{Ca}^{2+}$ signal transduction. J Biol Chem 267:13361-13368.

Abeliovitch A, Paylor R, Chen C, Kim J, Wehner JM, Tonegawa S (1993) $\mathrm{PKC} \gamma$-mutant mice exhibit mild deficits in spatial and contextual learning. Cell 75:1263-1271.

Aiba A, Chen C, Herrup K, Rosenmund C, Stevens CF, Tonegawa S (1994) Reduced hippocampal long-term potentiation and context-specific deficit in associative learning in mGluR1 mutant mice. Cell 79:365-375.

Bach ME, Hawkins RD, Osuman M, Kendel ER, Mayford M (1995) Impairment of spatial but not contextual memory in CaMKII mutant mice with a selective loss of hippocampal LTP in the range and theta frequency. Cell 81:905-910.

Bannerman DM, Good MA, Butcher SP, Ramsay M, Morris RG (1995) Distinct components of spatial learning revealed by prior training and NMDA receptor blockade. Nature 378:182-186.

Bashir ZI, Bortolotto ZA, Davies CH, Berretta N, Irving AJ, Seal AJ, Henley JM, Jane DE, Watkins JC, Collingridge GL (1993) Induction of LTP in the hippocampus needs synaptic activation of glutamate metabotropic receptors. Nature 363:347-350.

Baude A, Nussen Z, Roberts JD, Mulvihill E, McIlhinney RAJ, Somogyi $\mathrm{P}$ (1993) The metabotropic glutamate receptor mGluR1 $\alpha$ is concentrated at presynaptic membranes of neuronal subpopulations as detected by immunogold reaction. Neuron 11:771-787.

Bliss TVP, Collingridge GL (1993) A synaptic model of memory: longterm potentiation in the hippocampus. Nature 361:31-39.

Bortolotto ZA, Bashir ZI, Davies CH, Collingridge GL (1994) Molecular switch activated by metabotropic glutamate receptors regulates induction of long-term potentiation. Nature 368:740-743.

Bourtchuladze R, Frenguelli B, Blendy J, Cioffi D, Schutz G, Silva AJ (1994) Deficient long term memory in mice with a targeted mutation of the cAMP-responsive element kindling protein. Cell 79:59-68.

Chinestra P, Aniksztejn L, Diabira D, Ben-Ari Y (1993) RS- $\alpha$-methyl-4curloxyphenylglycine neither prevents induction of LTP nor antagonizes metabotropic glutamate receptors in CA1 hippocampal neurons. J Neurophysiol 70:2684-2689.

Conquet F, Bashir ZI, Davies CH, Daniel H, Ferraguti F, Bordi F, Franz-Bacon K, Reggiani A, Matarese V, Condé F, Collingridge G, Crépel F (1994) Motor deficit and impairment of synaptic plasticity in mice lacking GluR1. Nature 372:237-243.

Davis S, Butcher SP, Morris RG (1992) The NMDA receptor antagonist D-2-amino-5-phosphonopentanoate (D-AP5) impairs spatial learning and LTP in vivo at intracerebral concentrations comparable to those that block LTP in vitro. J Neurosci 12:1:21-34.

Gereau RW, Conn PJ (1995) Roles of specific metabotropic glutamate receptor subtypes in regulation of hippocampal cell CA1 pyramidal excitability. J Neurophysiol 74:122-129.

Gerlai R, Wojtowicz J, Marks A, Roder J (1995) Over-expression of a calcium binding protein $\mathrm{S} 100 \mathrm{~b}$, in astrocytes alters synaptic plasticity and impairs spatial learning in transgenic mice. Learn Mem 2:26-39.

Grant SG, O’Dell T, Karl K, Sleio PC, Soriano P, Kandel E (1992) Impaired long term potentiation, spatial learning and hippocampal development in fyn mutant mice. Science 258:1903.

Huang YY, Kendel ER, Varshavoksy L, Brandon EP, Ming Q, Idzerdo EP, McKnight S, Bourtchuladze R (1995) A genetic test of the effects of mutations in PKA on mossy fiber LTP and its relation to spatial and contextual learning. Cell 83:1211-1222.
Janus C, Janus M, Roder J (1995) Spatial exploration in transgenic mice expressing human $\beta$-S100. Neurobiol Learn Mem 64:58-67.

Jia ZP, Agopyan N, Miu P, Xiong Z, Henderson J, Gerlai R, Taverna F, Velumian A, MacDonald J, Carlen P, Abramow-Newerly W, Roder J (1996) Enhanced LTP in mice deficient in the AMPA receptor, GluR2. Neuron 17:945-956.

Manzoni OJ, Weisskopf MG, Nicoll RA (1994) MCPG antagonizes metabotropic glutamate receptors but not long-term potentiation in the hippocampus. Eur J Neurosci 6:1050-1054.

Martinez J, Derrick B (1996) Long-term potentiation and learning. Annu Rev Psychol 47:173-203.

Mayford M, Bach ME, Huang YY, Wang L, Hawkins R, Kandel E (1996) Control of memory formation through regulated expression of a CaMKII transgene. Science 274:1678-1683.

Minikami R, Katsuki F, Suguyama H (1993) A variant of metabotropic glutamate receptor subtype 5: an evolutionally conserved insertion with no termination codon. Biochem Biophys Res Commun 194:622-627.

Molinari S, Battini R, Ferrari S Pozzi L, Koillcross A, Robbins T, Jouvenceau A, Billard Dutor P, Lamour Y, Baker W, Cox H, Emson P (1996) Deficits in memory and hippocampal LTP in mice with reduced calbindin D28K-expression. Proc Natl Acad Sci USA 93:8028-8033.

Morris RGM (1990) Toward a representative hypothesis of the role of hippocampal synaptic plasticity in spatial and other forms of learning. Cold Spring Harbor Symp Quant Biol 55:161-173.

Nagy A, Rossant J, Nagy R, Abramow-Newerly W, Roder JC (1993) Derivation of completely cell culture-derived mice from early-passage embryonic stem cells. Proc Natl Acad Sci USA 90:8424-8428.

Nakanishi S (1994) Metabotropic glutamate receptors: synaptic transmission, modulation and plasticity. Neuron 13:1031-1037.

Nicoll RA, Malenka RC (1995) Contrasting properties of two forms of long-term potentiation in the hippocampus. Nature 3707:115-118.

Nosten-Bertrand M, Errington ML, Murphy KPS, Tokugawa Y, Barloni E, Kozlova E, Michalovitch D, Morris RGM, Silver J, Stewart CJ, Bliss TVP, Morris RJ (1996) Normal spatial learning despite regional inhibition of LTP in mice lacking thy 1. Nature 379:826-829.

O'Connor JJ, Rowan MJ, Anwyl R (1995) Tetanus-induced a similar increase in the AMPA and NMDA receptor components of the excitatory postsynaptic current: investigations of the involvement of mGlu receptors. J Neurosci 15:2013-2020.

Philips RG, LeDoux JE (1992) Differential contribution of amygdala and hippocampus to cued and contextual fear conditioning. Behav Neurosci 106:274-285.

Pin JP, Duvoisin R (1995) The metabotropic glutamate receptors: structure and functions. Neuropharmacology 34:1-26.

Richter-Levin G, Errington ML, Megawe H, Bliss TVP (1994) Activation of metabotropic glutamate receptors is necessary for long-term potentiation in the dentate gyrus and for spatial learning. Neuropharmacology 33:853-857.

Riedel G (1996) Function of metabotropic glutamate receptors in learning and memory. Trends Neurosci 19:219-224.

Riedel G, Reymann K (1993) An antagonist of the metabotropic glutamate receptor prevents LTP in the dentate gyrus of free moving rats. Neuropharmacology 32:929-931.

Romano C, Sesmu M, McDonald CT, O’Malley K, Van der Pol A, Olney J (1995) Distribution of metabotropic glutamate receptor mGluR5 immunoreactivity in rat brain. J Comp Neurol 355:455-469.

Sakimura K, Kutsuwasle T, Ho I, Manabe T, Takayama C, Kushiya E, Yago T, Azawa S, Inouye Y, Suizyama H, Mishina M (1995) Reduced hippocampal LTP and spatial learning in mice lacking NMDA receptor $\epsilon /$ subunit. Nature 373:151-155.

Saucier D, Cain DP (1995) Spatial learning without NMDA receptordependent long-term potentiation. Nature 378:186-189.

Shigemoto R, Nomura S, Ohishi H, Sugihara H, Nakanishi S, Mizuno N (1993) Immunohistochemical localization of a metabotropic glutamate receptor, mGluR5, in the rat brain. Neurosci Lett 163:53-57.

Silva AJ, Stevens CF, Tonegawa S, Wang Y (1992) Deficient hippocampal long-term potentiation in $\alpha$-calcium-calmodulin kinase II mutant mice. Science 257:201-206.

Stevens J (1992) Applied multivariate statistics for the social sciences, Ed 2. Hillsdale, NJ: Lawrence Erlbaum Associates.

Tsien JZ, Chen DF, Gerber D, Tom C Mercer EH, Anderson JA, Mayford M, Kandel ER, Tonegawa S (1996) Subregion-and cell typerestricted gene knockout in mouse brain. Cell 87:1317-1326.

Zheng F, Gallagher JP (1992) Metabotropic glutamate receptors are required for the induction of long-term potentiation. Cell 9:163-172. 